\title{
THERMOELASTIC ANALYSIS OF HYDRO- STATIC THRUST BEARINGS FOR HYDRAULIC EQUIPMENT
}

\author{
T. Kazama, A. Yamaguchi, S. Shimizu
}

Dept. of Mechanical Engineering and Materials Science

Yokohama National University

Yokohama, Japan

\section{ABSTRACT}

The thermoelastic behavior of hydrostatic thrust bearings is analyzed numerically. Mineral oils, HWCF, sea water, and tap water are studied as lubricants. The physical properties of lubricants are expressed as a function of temperature and pressure. The heat transfer and thermoelastic distortion of the bearing pad are considered. The performance of bearings is evaluated by the load carrying capacity, mass flow rate, and friction torque. The effect of temperature and pressure on the physical properties of mineral oils is greater than that on HWCF, sea water, and tap water. The load carrying capacity is scarcely influenced by the types of lubricant, the angular velocity, and the fluid film profile. The fluid film thickness influences the mass flow rate and the friction torque. The inclination of the bearing pad increases the mass flow rate and the moment-load carrying capacity. The distortion due to pressure in the fluid film increases the mass flow rate.

\section{KEYWORDS}

Hydraulic Equipment, Hydrostatic Thrust Bearings, Lubricant, Thermoelastic Distortion

\section{NOMENCLATURE}

$\begin{array}{lll}A & \text { thermal expansivity } & {[1 / \mathrm{K}]} \\ c_{p} & \text { specific heat at constant pressure }[\mathrm{J} /(\mathrm{kg} \mathrm{K})] \\ H & \text { thickness of the bearing pad } & {[\mathrm{m}]} \\ h & \text { film thickness } & {[\mathrm{m}]} \\ h_{c} & \text { film thickness at center } & {[\mathrm{m}]} \\ h_{0} & \text { coefficient of heat transfer } & {\left[\mathrm{W} /\left(\mathrm{m}^{2} \mathrm{~K}\right)\right]} \\ M & \text { moment-load carrying capacity } & {[\mathrm{N} \mathrm{m}]} \\ N & \text { friction torque } & {[\mathrm{N} \mathrm{m}]} \\ P & \text { pressure } & {[\mathrm{Pa}]} \\ p_{1} & \text { pocket pressure } & {[\mathrm{Pa}]} \\ P_{e} & \text { Pecklet number } & {[\mathrm{kg} / \mathrm{s}]} \\ Q & \text { mass flow rate } & \end{array}$

$\begin{array}{lll}R_{1} & \text { pocket radius of the bearing pad }[\mathrm{m}] \\ R_{2} & \text { outer radius of the bearing pad }[\mathrm{m}] \\ r, \theta, z & \text { cylindrical co-ordinates of the fluid film } \\ r, \theta, z_{2} & \text { cylindrical co-ordinates of the bearing pad } \\ T & \text { temperature } & {[\mathrm{K}]} \\ T_{1} & \text { pocket temperature } & {[\mathrm{K}]} \\ T_{2} & \text { temperature of the bearing pad } & {[\mathrm{K}]} \\ u, v, w & \text { velocity components in } r, \theta, z \text { directions }[\mathrm{m} / \mathrm{s}] \\ W & \text { load carrying capacity } & {[\mathrm{N}]} \\ \gamma & \text { inclined angle of the bearing pad } & {[\mathrm{rad}]} \\ \lambda & \text { thermal conductivity } & {[\mathrm{W} /(\mathrm{m} \mathrm{K})]} \\ \Lambda & \text { thermal conductivity of the pad } & {[\mathrm{W} /(\mathrm{m} \mathrm{K})]} \\ \mu & \text { viscosity } & {[\mathrm{Pa} / \mathrm{s}]} \\ \rho & \text { density } & {\left[\mathrm{kg} / \mathrm{m}^{3}\right]} \\ \omega & \text { angular velocity } & {[\mathrm{rad} / \mathrm{s}]}\end{array}$

Subscripts

ambient or atomospheric condition standard condition

$$
\begin{array}{ll}
\bar{c}_{p}=\frac{c_{p}}{c_{p_{0}}} & \bar{h}=\frac{h}{h_{c}} \\
\bar{M}=\frac{h_{c}^{2}}{\mu_{0} \omega \theta_{0} \Delta R^{5}} M & \bar{N}=\frac{h_{c}}{\mu_{0} \omega \theta_{0} \Delta R^{4}} N \\
\bar{p}=\left(\frac{h_{c}}{\Delta R}\right)^{2} \omega \mu_{0} p & P_{c}=\frac{\rho c_{p_{0}} h_{c}^{2} \omega}{\lambda_{0}} \\
\bar{Q}=\frac{Q}{\rho_{0} \omega \theta_{0} h_{c} \Delta R^{2}} & \bar{r}=\frac{r}{\Delta R}-r_{0} \\
r_{0}=\frac{R_{1}}{\Delta R} & \bar{T}=\frac{T}{T_{0}} \\
\overline{T_{2}}=\frac{T_{2}}{T_{0}} & \bar{u}=\frac{u}{\Delta R \omega} \\
\bar{v}=\frac{v}{r \omega} & \bar{w}=\frac{w}{\Delta R \omega} \\
\bar{W}=\frac{h_{c}}{\omega \mu_{0} \Delta R^{3} \theta_{0}} W & \bar{z}=\frac{z}{h} \\
\overline{z_{2}}=\frac{z_{2}}{H} & \bar{\theta}=\frac{\theta}{\theta_{0}} \\
\theta_{0}=2 \pi & \Delta R=R_{2}-R_{1} \\
\bar{\lambda}=\frac{\lambda}{\lambda_{0}} & \bar{\mu}=\frac{\mu}{\mu_{0}} \\
\bar{\rho}=\frac{\rho}{\rho_{0}} &
\end{array}
$$




\section{INTRODUCTION}

Recently, the hydraulic equipment has been operating under high pressure and high speed. Furthermore, HWCF (High Water Content Fluid) is superseding the mineral oils for the mining and automobile industry. Sea water has been tested as lubricants in the field of the development of the ocean.

The thermal effects in hydrodynamic thrust bearings are studied in recent years(1). Hahn and Kettelbrough(2) analyzed the thermal effects on slider bearings. Huebner(3) investigated the three dimensional thermohydrodynamic(THD) effect of sector thrust bearings. They found that the effect of temperature on the viscosity is more significant than that of the distortion due to temperature and pressure. Kim, et al.(4) presented a THD study of tilting-pad thrust bearings. They took account of a three-dimensional change of the viscosity in the fluid film. Taniguchi and Ettles ( 5 ) studied the thermoelastohydrodynamic(TEHD) behavior of parallel sliders.

However, we have as yet little information about the thermal effects of hydrostatic thrust bearings. The design of hydrostatic thrust bearings for hydraulic equipment has been usually based on the assumption that the physical properties of the lubricants are independent on temperature and pressure.

The aim of this research is to clarify numerically the thermal effects of hydrostatic thrust bearings used mainly in hydraulic pumps and motors. This analysis is conducted for six types of lubricants, that is, the three types of mineral oils(the kinematic viscosity: $8.3,27.6$, and $281 \mathrm{~mm}^{2} / \mathrm{s}$ at $313 \mathrm{~K}$ and under $101.3 \mathrm{kPa}$ ), HWCF, sea water, and tap water. The physical properties of the lubricants are expressed as a function of temperature and pressure. The heat transfer between the bearing pad and both the lubricant and the circumference is taken into account. The thermal and elastic distortion of the bearing pad is also considered. The performance of bearings is evaluated by the load carrying capacity, mass flow rate, and friction torque.

\section{PHYSICAL PROPERTIES OF LUBRICANTS}

In the present study, the density, viscosity, specific heat at constant pressure, heat conductivity, and thermal expansivity of the lubricants are expressed as a function of temperature and pressure. These expressions are applicable to the range of $273 \mathrm{~K}-373 \mathrm{~K}$ and $0.1 \mathrm{MPa}$ -

$50.1 \mathrm{MPa}$. The physical properties of mineral oils are given by Eqs. (1) through (8). The constants in these equations, and the equations of HWCF, sea water, and tap water are listed in Appendix A.

\section{Density}

Kjфlle(6) proposed the following equation of the density of mineral oils.

1 Numbers in brackets designate References at end of paper.

$$
\begin{aligned}
& \rho(p, T)=\left(E_{0}\left[1-\left\{e^{-\frac{p-p_{0}}{E_{1}}}+E_{2}\left(p-p_{0}\right)\right\}\right]+D\right) \\
& \times\left(T-T_{0}\right)+\frac{\rho_{0}}{1-C \ln \left\{1+\frac{p-p_{0}}{B}\right\}}
\end{aligned}
$$

where $B, C, D, E_{0}, E_{1}, E_{2}$ are constants which depend on the type of mineral oils.

Viscosity

The viscosity is given by

$$
\mu(p, T)=\mu\left(p, T_{.}\right) \mu\left(p_{0}, T\right)
$$

The following walther equation(7) is used to represent the viscosity of the mineral oils under the atmospheric pressure.

$$
\log \log \left\{v\left(p_{e}, T\right)+C\right\}=-m_{0} \log T+N_{0}
$$

where $\mathrm{y} \mathrm{mm}^{2} / \mathrm{s}$ is the kinematic viscosity under the atmospheric pressure, $C=0.7$, and $\mathrm{m}_{\mathrm{O}}$ and $\mathrm{N}_{\mathrm{O}}$ are constants which are determined by the measured values. The empirical equation which describes the isothermal viscosity-pressure relationship is

$$
\mu\left(p, T_{a}\right)=\mu_{e} e^{\beta\left(p-p_{a}\right)}
$$

where $\beta$ is a coefficient of pressure which is given by So and Klaus $(8)$.

\section{Specific Heat at Constant Pressure}

The equation of the specific heat at constant pressure of the mineral oils is given by

$$
c_{p}(p, T)=c_{p}\left(p_{a}, T\right)-\int_{p_{a}}^{p} T \frac{\partial^{2}}{\partial T^{2}}\left(\frac{1}{p}\right) d p
$$

where,

$$
c_{p}\left(p_{a}, T\right)=A_{0}+A_{1} \cdot T
$$

where $A_{0}$ and $A_{1}$ are the constants which depend on the type of mineral oils.

\section{Thermal Conductivity}

The equation of the heat conductivity of the mineral oils is given by

$$
\lambda(p, T)=\lambda_{0}\left[1-\alpha\left(T-T_{0}\right)\right]\left[1-\beta\left(p-p_{0}\right)\right]
$$

where $\alpha$ is a coefficient of temperature and $\beta$ is a coefficient of pressure.

Thermal Expansivity

The thermal expansivity is defined as 


$$
\Lambda=\rho\left[\frac{\partial(1 / \rho)}{\partial T}\right]_{p}
$$

Table 1 summarizes the density, viscosity, specific heat at constant pressure, thermal conductivity, and thermal expansivity of the mineral oils of which kinematic viscosity are $8.3,27.6$, and $281 \mathrm{~mm}^{2} / \mathrm{s}$ at $313 \mathrm{~K}$ and under $101.3 \mathrm{kPa}$, the surfactant solution type HWCF with water content of $96.8 \%$, the sea water with water content of $96.5 \%$, and tap water at $313 \mathrm{~K}$ and under $101.3 \mathrm{kPa}$.

Figure 1 shows the measured values of the kinematic viscosity under the atmospheric pressure and the calculated values by the equations proposed in this paper. The calculated values agree well with the measured values. The effect of temperature on the kinematic viscosity of mineral oils are much greater than that of HWCF, sea water, and tap water. The kinematic viscosity of HWCF, sea water, and tap water are almost the same, and the change with temperature is resemble.

THEORY

The following assumptions are used:

(1) The hydrostatic thrust bearings are operating thermoelastohydrodynamically in the steady state.

(2) The lubricant is a Newtonian fluid.

(3) Pressure gradient across the film is negligible.

(4) The lubricant flow remains laminar.

(5) Cavitation does not occur.

(6) Radiant heat transfer from the bearing surfaces is negligible.

(7) Inertia and body force terms are negligible compared with the viscous and pressure terms in the momentum equations.

\section{BASIC EQUATIONS}

Consider a typical hydrostatic thrust bearing as shown in Fig. 2. The bearing body excluding the bearing pad is assumed to be rigid and isothermal.

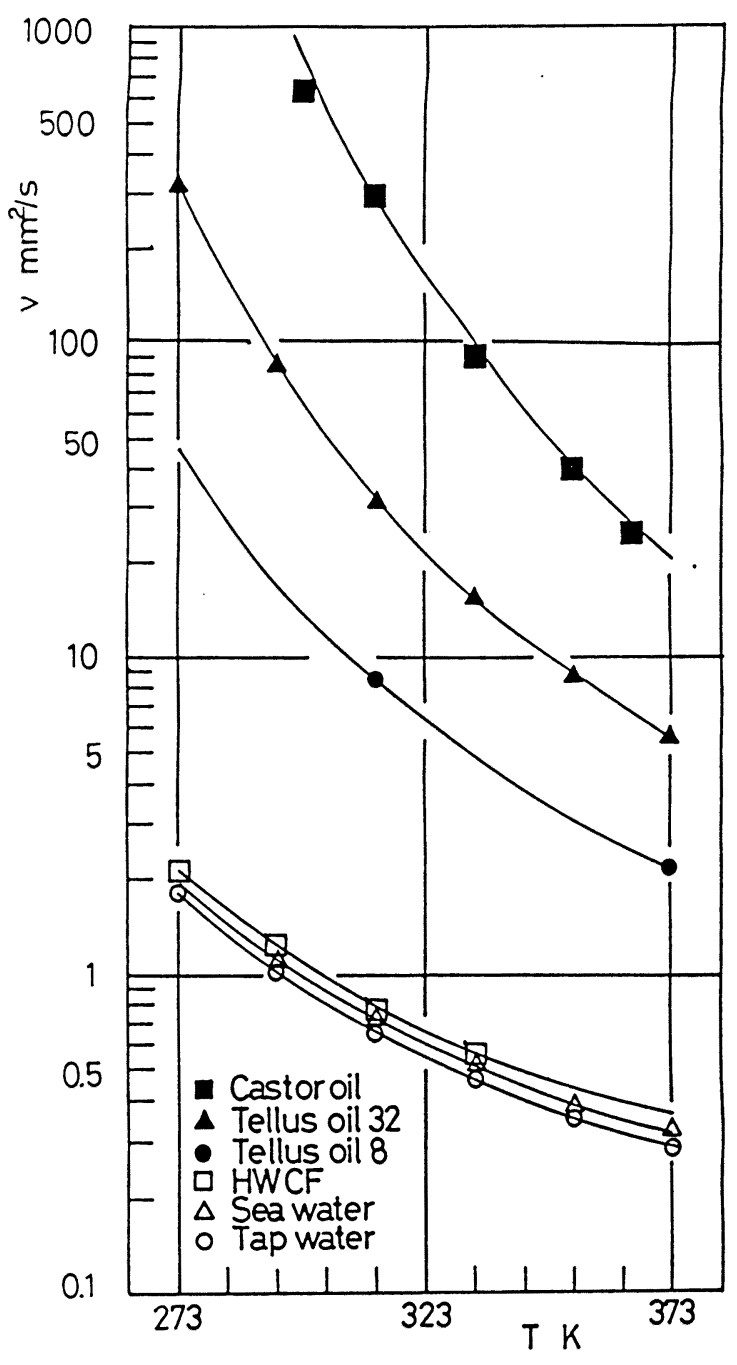

Fig. 1 Kinematic viscosity of lubricants

The nondimensionalized Reynolds equation taking account of the change in the physical properties of the lubricants in the fluid film is

Table 1 Physical properties of studied mineral oils, HWCF, water, and sea water at $313 \mathrm{~K}$ and under $101.3 \mathrm{kPa}$

\begin{tabular}{lccccc} 
& $\begin{array}{c}\rho \\
\mathrm{kg} / \mathrm{m}^{3}\end{array}$ & $\begin{array}{c}\mu \\
\mathrm{Pas}\end{array}$ & $\begin{array}{c}\mathrm{C}_{0} \\
\mathrm{~J} /(\mathrm{kg} \mathrm{K})\end{array}$ & $\begin{array}{c}\lambda \\
\mathrm{W} /(\mathrm{m} \mathrm{K})\end{array}$ & $\begin{array}{c}\mathrm{A} \\
1 / \mathrm{K}\end{array}$ \\
\hline Mineral oil & & $\times 10^{-3}$ & $\times 10^{3}$ & $\times 10^{-3}$ & $\times 10^{-4}$ \\
Low visc. & 863 & & & & \\
Med. visc. & 863 & 27.6 & 2.03 & 130 & 7.16 \\
High visc. & 960 & 281.0 & 2.03 & 130 & 7.16 \\
Water & $997^{\cdots} \cdots$ & 0.666 & $4.18^{\circ}$ & $599^{\circ}$ & 3.16 \\
HWCF & $997^{\circ} \cdots$ & 0.75 & $4.18^{\circ}$ & $599^{\circ}$ & 3.85 \\
Sea water & $976^{\circ} \cdots$ & $0.902^{\circ}$ & $3.90^{\circ}$ & $596^{\circ}$ & 3.85 \\
\hline
\end{tabular}

- values for $291 \mathrm{~K}$

-. values for $293 \mathrm{~K}$

-.. values for $298 \mathrm{~K}$ 


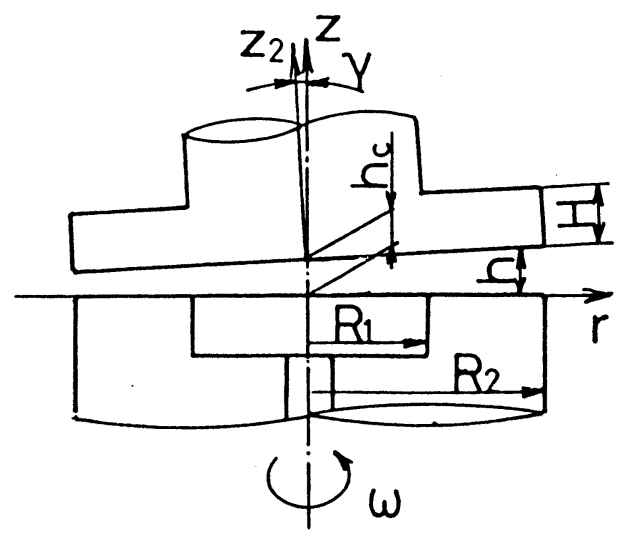

Fig. 2 Bearing configuration

$\frac{\partial}{\partial \bar{r}}\left\{\left(\bar{r}+r_{0}\right) \bar{h}^{3} \bar{F}_{2} \frac{\partial \bar{p}}{\partial \bar{r}}\right\}+\frac{1}{\theta_{0}^{2}} \overline{\bar{r}} \frac{1}{r_{0}} \frac{\partial}{\partial \bar{\theta}}\left\{\bar{h}^{3} \bar{F}_{2} \frac{\partial \bar{p}}{\partial \bar{\theta}}\right\}$

$=\frac{\bar{r}+r_{0}}{\theta_{0}} \bar{\rho} \frac{\partial \bar{h}}{\partial \bar{\theta}}-\frac{\bar{r}+r_{0}}{\theta_{0}} \frac{\partial}{\partial \bar{\theta}}\left[\frac{\bar{h} \bar{F}_{3}}{\bar{F}_{0}}\right]$

where

$$
\left.\begin{array}{l}
\bar{F}_{0}=\int_{0}^{1} \frac{\overline{d z}}{\bar{\mu}} \\
\bar{F}_{1}=\int_{0}^{1} \frac{\bar{z}}{\bar{\mu}} d \bar{z} \\
\bar{F}_{2}=\int_{0}^{1} \bar{\rho} \int_{0}^{1} \frac{\overline{d z}}{\bar{\mu}} d \bar{z} \\
\bar{F}_{3}=\int_{0}^{1} \bar{\rho} \int_{0}^{1} \frac{\bar{z}}{\bar{\mu}} d \bar{z} d \bar{z}
\end{array}\right\}
$$

The boundary conditions of Eq. (9) are

$$
\left.\begin{array}{l}
\bar{p}(0, \bar{\theta})=\bar{p}_{1} \\
\bar{p}(1, \bar{\theta})=\bar{p}_{c}
\end{array}\right\}
$$

The energy equation expressed by cylindrical coordinates is

$$
\begin{aligned}
& \frac{\partial^{2} \bar{T}}{\partial \bar{z}^{2}}+\left[\frac{1}{\bar{\lambda}} \frac{\partial \bar{\lambda}}{\partial \bar{\lambda}}+P_{c} \frac{\bar{\rho} \bar{c}_{p} \bar{h}^{2}}{\bar{\lambda}}\left(\bar{u} m_{r}+\frac{\bar{v}}{\theta_{0}} m_{0}-\frac{\bar{w}}{\bar{h}}\right)\right] \frac{\partial \bar{T}}{\partial \bar{\theta}} \\
& -P_{c} \frac{\bar{\rho} \bar{c}_{p} \bar{h}^{2}}{\bar{\lambda}} \bar{u} \frac{\partial \bar{T}}{\partial \bar{r}}-P_{e} \frac{\bar{\rho} \bar{c}_{p} \bar{h}^{2}}{\bar{\lambda}} \frac{\bar{v}}{\theta_{0}} \frac{\partial \bar{T}}{\partial \bar{\theta}} \\
& +\frac{\Delta R^{2} \omega^{2} \mu_{0}}{\lambda_{0} T_{0}} \frac{\bar{h}^{2}}{\bar{\lambda}}\left[\bar{\mu} \cdot \bar{\phi}-A \cdot T\left(\bar{u} \frac{\partial \bar{p}}{\partial \bar{r}}+\frac{\bar{v}}{\theta_{0}} \frac{\partial \bar{p}}{\partial \bar{\theta}}\right)\right]=0 \text { (12) }
\end{aligned}
$$

Considering the distortion of the fluid film profile, the operators in Eq. (12) are given by (10)

$$
\begin{aligned}
& \frac{\partial}{\partial r}=\frac{1}{\Delta R}\left[\frac{\partial}{\partial \bar{r}}-m_{r} \frac{\partial}{\partial \bar{z}}\right] \\
& \frac{\partial}{\partial \theta}=\frac{1}{\theta_{0}}\left[\frac{\partial}{\partial \bar{\theta}}-m_{1} \frac{\partial}{\partial \bar{z}}\right] \\
& \frac{\partial}{\partial z}=\frac{1}{h_{c}} \frac{\partial}{\bar{h} \partial \bar{z}}
\end{aligned}
$$

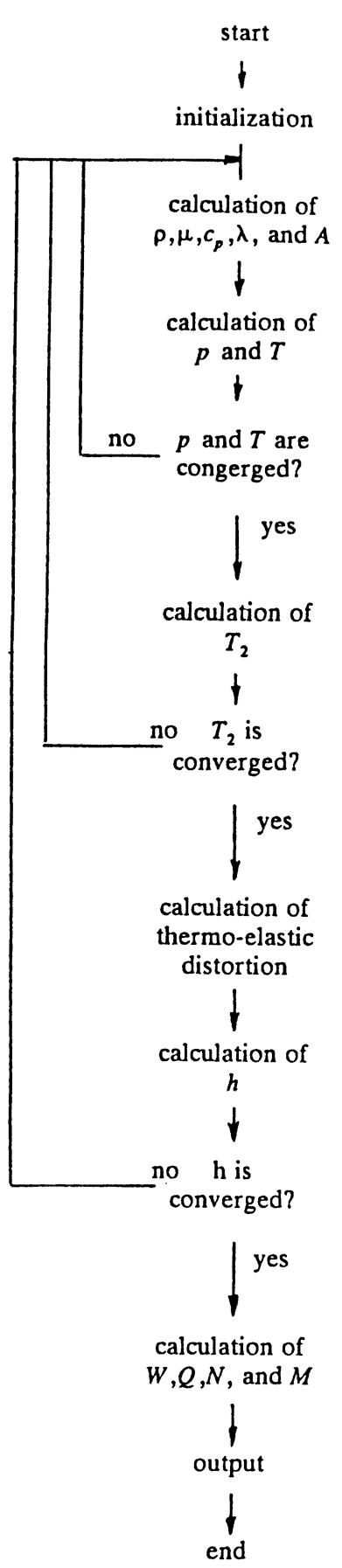

Fig. 3 Scheme of calculation for TEHD solution

where

$$
\left.\begin{array}{l}
m_{r}=\frac{\bar{z}}{\bar{h}} \frac{\partial \bar{h}}{\partial \bar{r}} \\
m_{c}=\frac{\bar{z}}{\bar{h}} \frac{\partial \bar{h}}{\partial \bar{\theta}}
\end{array}\right\}
$$

The heat conduction equation of the bearing pad is

$$
\left(\bar{r}+r_{0}\right) \frac{\partial}{\partial \bar{r}}\left[\left(\bar{r}+r_{0}\right) \frac{\partial \bar{T}_{2}}{\partial \bar{r}}\right]+\frac{1}{\theta_{0}^{2}} \frac{\partial^{2} \bar{T}_{2}}{\partial \bar{\theta}^{2}}+\left[\frac{\bar{r}+r_{0}}{\Delta R H}\right]^{2} \frac{\partial^{2} \bar{T}_{2}}{\partial \bar{z}_{2}^{2}}=0
$$


The thermal boundary conditions of the energy and heat conduction equations are specified by the continuity of the heat flux at the fluid-solid and the solidambient boundaries. Thus,

$$
\left.\begin{array}{l}
\bar{T}_{2}\left(0, \bar{\theta}, \bar{z}_{2}\right)=\bar{T}_{1} \\
\bar{T}(\bar{r}, \bar{\theta}, 0)=\bar{T}_{1} \\
\bar{T}(0, \bar{\theta}, \bar{z})=\bar{T}_{1} \\
\bar{T}(\bar{r}, \bar{\theta}, 1)=\bar{T}_{2}(\bar{r}, \bar{\theta}, 0) \\
-\left.\bar{\lambda} \frac{\partial \bar{T}_{1}}{\partial \bar{z}}\right|_{\bar{z}-1}=-\left.\bar{\Lambda} \frac{\partial \bar{T}_{2}}{\partial \bar{z}_{2}}\right|_{\bar{z}_{2}-0} \\
-\left.\bar{\Lambda} \frac{\partial \bar{T}_{2}}{\partial \bar{r}_{\bar{r}-1}}\right|_{\bar{r}}=-\bar{h}_{0}\left[\bar{T}_{a}-\bar{T}(1, \bar{\theta}, \bar{z})\right] \\
-\left.\bar{\Lambda} \frac{\partial \bar{T}_{2}}{\partial \bar{z}_{2}}\right|_{\bar{z}_{2}-1}=-\bar{h}_{0}\left[\bar{T}_{a}-\bar{T}(\bar{r}, \bar{\theta}, 1)\right]
\end{array}\right\}
$$

For the inclined and rigid bearing pad, the fluid film thickness is

$$
\bar{h}=1-\frac{\Delta R}{h_{c}}\left(\bar{r}-r_{0}\right) \gamma \cos \left(\theta_{0} \bar{\theta}\right)
$$

The bearing performance is evaluated by the load carrying capacity, moment-load carrying capacity, mass flow rate, and friction torque. That is, these values are given by

\begin{tabular}{|c|c|c|}
\hline E & 209.0 & $\mathrm{GPa}$ \\
\hline$h_{B}$ & 50.0 & $W /\left(m^{2} \quad K\right)$ \\
\hline p. & 101.3 & $\mathrm{kPa}$ \\
\hline$p_{1}$ & 10.1 & $\mathrm{MPa}$ \\
\hline$R_{1}$ & 50.0 & $\mathrm{~mm}$ \\
\hline$R_{2}$ & 100.0 & $\mathrm{~mm}$ \\
\hline $\mathrm{T}_{0}$ & 293.2 & K \\
\hline$T_{1}$ & 313.2 & k \\
\hline$\alpha_{2}$ & $12.2 \times 10^{-8}$ & $1 / K$ \\
\hline$\Lambda$ & 54.0 & $W /(m K)$ \\
\hline$\sigma$ & 0.29 & \\
\hline
\end{tabular}

$$
\begin{aligned}
\bar{W} & =\int_{0}^{1} \int_{0}^{1} \bar{p}\left(\bar{r}+r_{0}\right) d \bar{\theta} d \bar{r}+\frac{\pi h_{c}\left(R_{2}^{2}-R_{1}^{2}\right) p_{1}}{\omega \mu_{0} \Delta R^{3} \theta_{0}} \\
\bar{M} & =\left[\left\{\int_{0}^{1} \int_{0}^{1}\left(\bar{r}+r_{0}\right)^{2} \bar{p} \cos \left(\theta_{0} \bar{\theta}\right) d \bar{\theta} d \bar{r}\right\}^{2}\right. \\
& \left.+\left\{\int_{0}^{1} \int_{0}^{1}\left(\bar{r}+r_{0}\right)^{2} \bar{p} \sin \left(\theta_{0} \bar{\theta}\right) d \bar{\theta} d \bar{r}\right\}^{2}\right]^{\frac{1}{2}} \\
\bar{Q} & =\left(\bar{r}+r_{0}\right) \bar{h} \int_{0}^{1} \int_{0}^{1} \bar{\rho} \bar{u} d \bar{\theta} d \bar{z}
\end{aligned}
$$

Table 2 Bearing dimensions and operating conditions

E : Young's modulus

$\alpha_{2}$ : thermal expansivity of the bearing pad

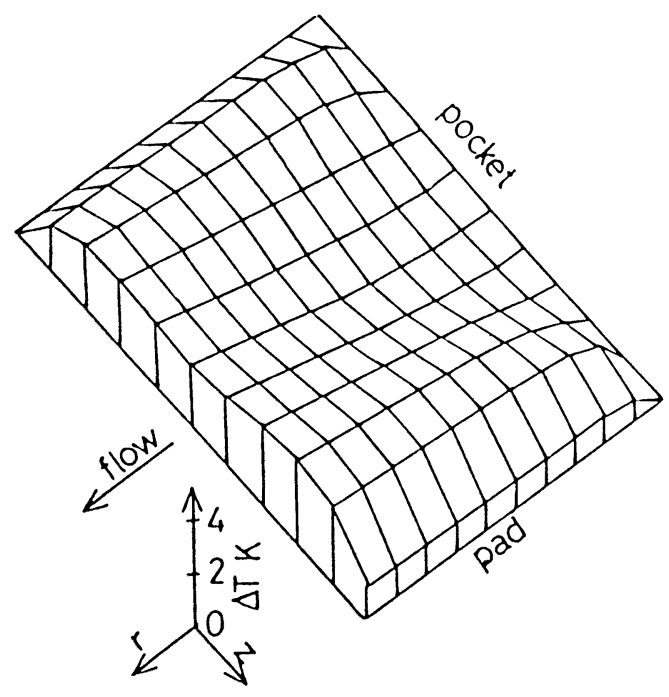

Mineral oil (Med. visc.)

$$
\begin{aligned}
& \mathrm{h}: \text { const. } \\
& \mathrm{h}_{\mathrm{c}}=0.1 \mathrm{~mm} \\
& \mathrm{H}=15.0 \mathrm{~mm} \\
& \omega=200.0 \mathrm{rad} / \mathrm{s}
\end{aligned}
$$

Fig. 4 Temperature distribution in the fluid film

\section{NUMERICAL ANALYSIS}

The Reynolds equation, energy equation, and heat conduction equation were solved by finite difference method(FDM) with iterative scheme. The thermoelastic distortion of the bearing pad was analyzed by finite element method(FEM). The scheme of the calculation is shown in Fig. 3. The convergence condition is that the errors of the temperature and pressure distribution are less than $e\left(=10^{-2}\right)$. The bearing dimensions and the operating conditions are listed in Table 2.

Figure 4 shows the temperature distribution in the fluid film. The temperature distribution is dominated by the radial and circumferential velocity distribution, and the heat conduction between the fluid in the middle of the film and the fluid adjacent the walls. The fluid temperature adjacent the walls is high, because the gradient of the radial velocity in these regions is large.

Figure 5 shows the effects of the types of lubricant on the load carrying capacity, mass flow rate, and friction torque. The types of lubricant influence scarcely the load carrying capacity, but remarkably the mass flow rate and friction torque. In the case of the physical properties being constant, the mass flow rate is in proportion to the viscosity and the friction torque is in inverse proportion to the viscosity. In Fig. 5 it is seen that the effect of the physical properties of the lubricants on the mass flow rate and friction torque is clearly more complicated. 


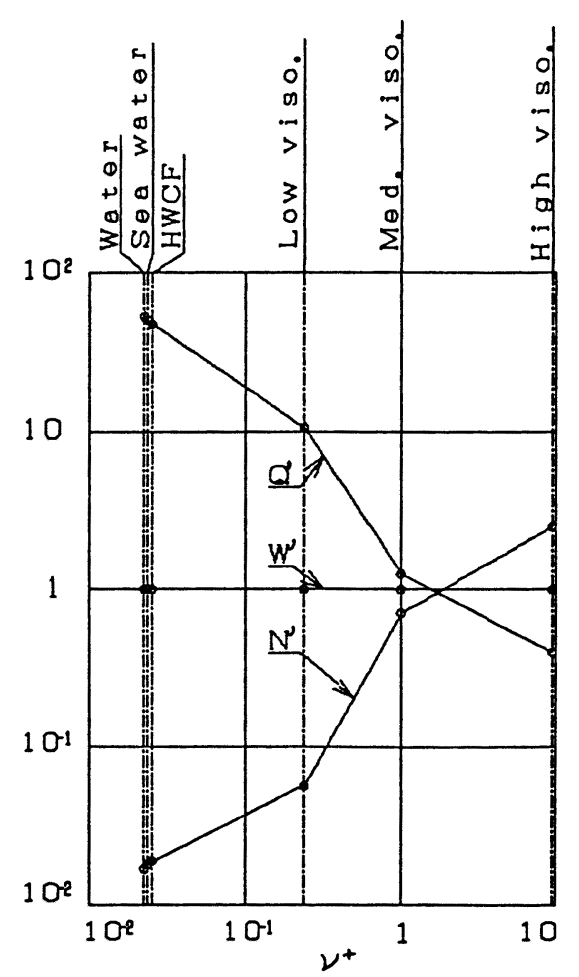

Fig. 5 Effects of lubricants on $W^{\prime}, Q^{\prime}$, and $N^{\prime}$ (normalized by $W, Q$, and $N$ of mineral oil (medium visc.) $\omega=200 \mathrm{rad} / \mathrm{s}, \mathrm{hc}=0.1 \mathrm{~mm}, \mathrm{~h}=$ const.

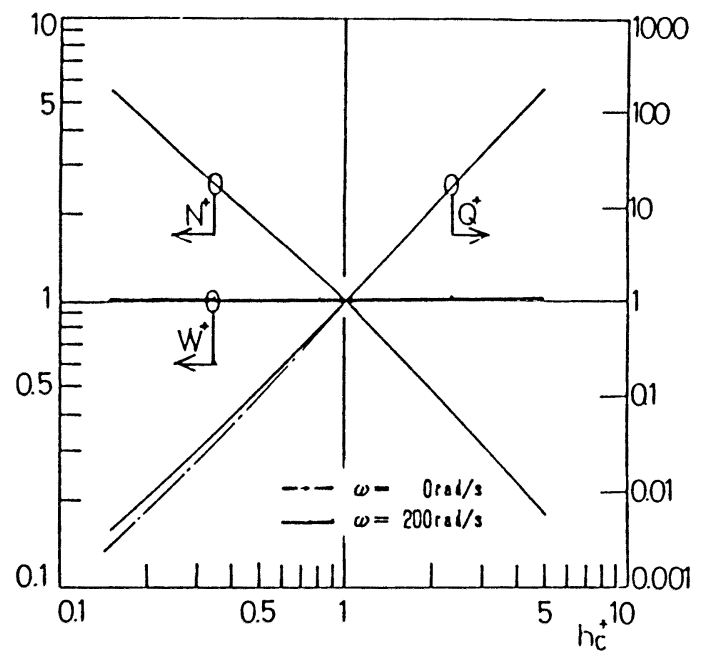

Fig. 6 Effects of film thickness on $W^{\prime}, Q^{\prime}$, and $N^{\prime}$ (normalized by $W, Q$, and $N$ of $h c=0.1 \mathrm{~mm})$

Figure 6 shows the effects of the fluid film thickness on the load carrying capacity, mass flow rate, and friction torque. The fluid film thickness influences scarcely the load carrying capacity. In the case of the physical properties being constant, the mass flow rate is in proportion to the third power of the fluid film thickness, and the friction torque is in inverse proportion to the fluid film thickness. When the thickness of the fluid film is thin, the change in the physical properties of lubricants is small, because the heat is easily

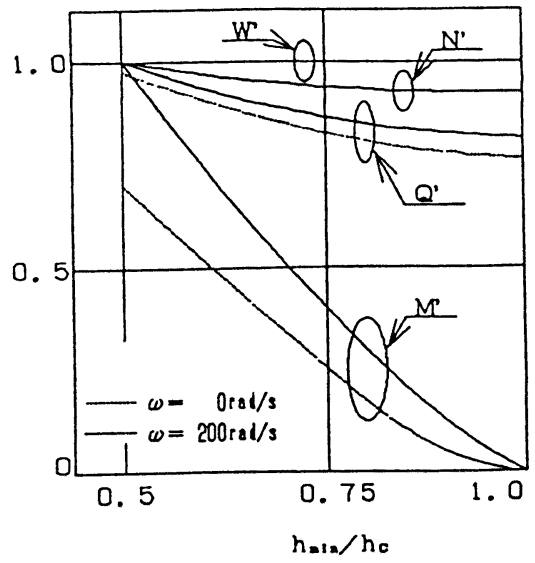

Fig. 7 Effects of inclination of the bearing pad on $W^{\prime}, M^{\prime}, Q^{\prime}$, and $N^{\prime}$ (normalized by $W, M, Q$, and $N$ of $\omega=0 \mathrm{rad} / \mathrm{s}$ and $\mathrm{hmin} / \mathrm{hc}=0.5)$ $\mathrm{hc}=0.1 \mathrm{~mm}$, rigid bearing pad

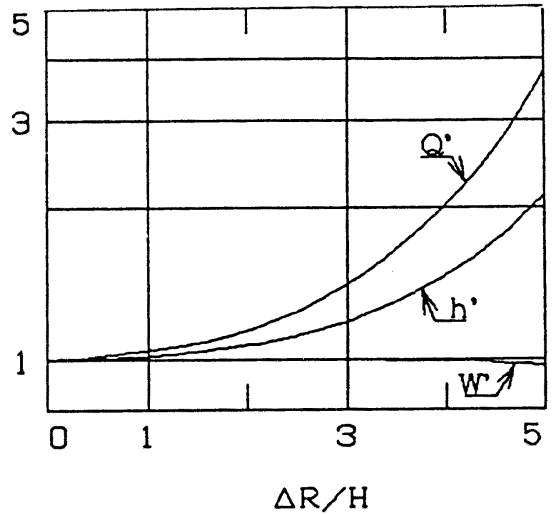

Fig. 8 Effects of thermoelastic distortion on $W^{\prime}$ and $Q^{\prime}$ (normalized by $W$ and $Q$ of rigid bearing pad) $h^{\prime}=$ hout/hc, $\omega=0 \mathrm{rad} / \mathrm{s}, h c=0.1 \mathrm{~mm}, \boldsymbol{\gamma}=0 \mathrm{rad}$

transported across the fluid film.

Figure 7 shows the effects of the thermoelastic distortion of the bearing pad on the load and moment-load carrying capacity, mass flow rate, and friction torque. The load carrying capacity is scarcely influenced by the inclination of the bearing pad. The inclination of the bearing pad increases the mass flow rate and moment-load carrying capacity. The mass flow rate for the rotational bearing pad is greater than that for the nonrotational bearing pad.

Figure 8 shows the effect of the 
distortion of the fluid film profile on the load carrying capacity and mass flow rate through varying the bearing pad thickness. The thin bearing pad causes the distortion of the fluid film profile due to pressure distribution in the fluid film. The effect of the distortion of the fluid film on the mass flow rate is greater than that on the load carrying capacity.

\section{CONCLUSIONS}

The thermoelastohydrodynamic behavior of hydrostatic thrust bearings mainly used for hydraulic equipment was analyzed numerically. Mineral oils, HWCF, sea water, and tap water were studied as lubricants. The physical properties of lubricants was expressed as a function of temperature and pressure. The performance of bearings was evaluated by the load carrying capacity, moment-load carrying capacity, mass flow rate, and friction torque. The calculated values of the physical properties of the lubricants agree well with the measured values. The effect of temperature and pressure on the physical properties of mineral oils is greater than that of HWCF, sea water and tap water. The load carrying capacity is scarcely influenced by the types of lubricant, the angular velocity, and the fluid film profile. The inclination of the bearing pad influences the mass flow rate and moment-load carrying capacity. When the thickness of the bearing pad decreases, the fluid film profile is distorted by the pressure distribution, therefore, the mass flow rate is increased.

\section{ACKNOWLEDGMENT}

The authors would like to express appreciation to $\mathrm{Mr}$. H. Murao and $\mathrm{Dr}$. N. Yoshinaga of the University of Tokyo, and $\mathrm{Mr}$. J. I. Yanagihara of Yokohama National University.

\section{REFERENCES}

(1) M. M. Khonsari, "A Review of Thermal Effects in Hydrodynamic Bearings, Part I: Slider and Thrust Bearings," ASLE Prep., No. 86-AM-2A-3, (1986), 1.

(2) E. J. Hahn, and C. F. Kettleborough, "Solution for the Pressure and Temperature in an Infinite Slider Bearing of Arbitrary Profile," Trans. ASME, J. Lubr. Technol., (1967), 445.

(3) K. H. Huebner, "A Three-Dimensional Thermohydrodynamic Analysis of Sector Thrust Bearings," ASLE Trans., 17-1, (1974), 62.

(4) K. W. Kim, M. Tanaka, and Y. Hori, "A Three-Dimensional Analysis of Thermohydrodynamic Performance of Sector-Shaped, Tilting-Pad Thrust Bearings," Trans. ASME, J. Lubr. Technol., 105, (1983), 406.

(5) S. Taniguchi and C. Ettles, "A ThermoElastic Analysis of the Parallel Surface Thrust Washer," ASLE Trans., 18-4, (1975), 299.

(6) A. Kjфlle, "Relations of the Properties of Fluid Power Oils for Thermodynamic
Measurements," VL. Report No.10.145, Water Power Laboratory, NTH. Trondheim (1976-8)

(7) ASTM, "Viscosity-Temperature Charts for Liquid Petroleum Products," D341-77, Annual Book of ASTM Standards, (1982)

(8) B. Y. C. So and E. E. KI a us, "Viscosity-Pressure Correlation of Liquids," ASLE Trans., 23-4, (1980), 409.

(9) M. C. Jeng, G. R. Zhou, and A. Z. Szeri, "A Thermohydrodynamic Solution of Pivoted Thrust Pads: Part I-Theory," Trans. ASME, J. Trib., 108, (1986), 195.

(10) I. Tanishita, A. Nagashima, and Y. Murai, "Correlation of Viscosity, Thermal Conductivity and Prandtl Number for Water and Steam as a Function of Temperature and Pressure," Bull. JSME, 14-77, (1971), 1187.

(11) "CRC Handbook of Chemical and Physics," 62nd ed. (1981-1982), F-6.

(12) Soc. Chem. Eng. Japan (ed.), "Busseiteisuu (Physico-chemical Properties), (in Japanese), 10, MARUZEN, (1972)

\section{APPENDIX A.}

The physical properties (density, viscosity, specific heat at constant pressure, and thermal conductivity) of mineral oils, HWCF, tap water, and sea water are described as follows.

Density of mineral oils $\underline{(6)}$

$$
\begin{aligned}
& p(p, T)=\left(0.270 \times\left[1-\left\{e^{-\frac{p-p_{0}}{-1.15 \times 10^{8}}}\right.\right.\right. \\
& \left.\left.\left.-0.134 \times 10^{-9}\left(p-p_{0}\right)\right\}\right]-0.618\right)\left(T-T_{0}\right)
\end{aligned}
$$

$$
+\frac{\rho_{0}}{1-0.215 \times \ln \left\{1+\frac{p-p_{0}}{1.72 \times 10^{8}}\right\}}
$$

\begin{tabular}{rr} 
Mineral oil & $\rho_{0} \mathrm{~kg}_{\mathrm{g}} / \mathrm{m}^{3}$ \\
\hline Low viscosity & 863 \\
Medium viscosity & 863 \\
High viscosity & 960
\end{tabular}

Density of tap water(11) and HWCF

$$
p(p, T)=p(T) \cdot e^{\beta \cdot(p-p)}
$$

where

$$
\begin{aligned}
& \beta=\frac{997.8+16.9 \cdot t-7.99 \times 10^{-3} \cdot t^{2}}{1+16.9 \times 10^{-3} \cdot t} \times 10^{-11} \\
& p(T)=\frac{50.88+0.616 \cdot t+1.46 \times 10^{-3} \cdot t^{2}}{1+19.7 \times 10^{-3} \cdot t} \\
& t=T-273.2
\end{aligned}
$$


564

Density of sea water(12)

$$
\begin{aligned}
& \rho(T)=1000+\sigma_{t} \\
& \sigma_{t}=-\frac{(t-3.98)^{2}}{503.57} \frac{t+273}{t+67.26} \\
& +51.3 \times\left\{1-t\left(4.79-9.82 \times 10^{-2} \cdot t\right) \times 10^{-3}\right. \\
& \left.+51.1 t(18.0-0.816 \cdot t) \times 10^{-6}\right\}
\end{aligned}
$$

Viscosity of mineral oils(7)(8)

$$
\begin{aligned}
& \mu(p, T)=e^{\beta \cdot\left(p-p_{0}\right)}\left\{\frac{-0.618}{p_{c}} t+1\right\} \frac{10^{N_{0} T^{-m_{0}}}-C}{v_{c}} \\
& \beta=\left[1.216+4.143\left\{\log \left(v_{0} \times 10^{-6}\right)\right\}^{3.0627}\right. \\
& +2.848 \times 10^{-4} m_{0}^{5.1903}\left\{\log \left(v_{0} \times 10^{-6}\right)\right\}^{1.5976} \\
& \left.-3.999 \times\left\{\log \left(v_{0} \times 10^{-6}\right)\right\}^{3.0795} p_{0}^{0.1162}\right] \times 10^{-8}
\end{aligned}
$$

\begin{tabular}{lrr} 
Mineral oil & $\rho_{\text {e }} \mathrm{kg}^{\prime} \mathrm{m}^{3}$ & $\nu_{,} \mathrm{m} \mathrm{m}^{2} / \mathrm{s}$ \\
\hline Low viscosity & 863 & 8.3 \\
Medium viscosity & 863 & 32.0 \\
High viscosity & 960 & 293.0
\end{tabular}

Viscosity of tap water(10)

$$
\mu(p, T)=\sum_{i=0}^{3} A_{1} p^{1}
$$

where

$$
\begin{aligned}
& A_{0}=\frac{1}{\sum_{t=0}^{4} A_{01} r^{2}}+\frac{A_{05}}{(t-20)^{2}+A_{06}}+A_{07} \\
& A_{1}=A_{10}+\frac{A_{11}}{(t-500)^{2}+A_{12}}+\frac{A_{13}}{(t+100)^{10}} \\
& A_{2}=A_{20}+\frac{A_{21}}{(t-490)^{2}+A_{22}}+\frac{A_{23}}{(t+100)^{10}} \\
& A_{3}=\sum_{i=0}^{1} A_{31} t^{t}+\frac{A_{32}}{(t-475)^{2}+A_{33}}+\frac{A_{34}}{(t+100)^{10}}
\end{aligned}
$$

Viscosity of sea water(12)

$$
\mu(p, T)=10^{0.124+0.979108 r_{\text {merer }}}
$$

Viscosity of HWCF

$$
\begin{aligned}
& \mu(p, T)=e^{6.54 \times 10^{-12}\left(p-p_{a}\right)} \rho_{a} \\
& \quad \times\left\{10^{10.57-658 \mathrm{kog} T}-0.7-e^{-1.47-1.84 r-0.51 v^{2}}\right\}
\end{aligned}
$$

Specific heat at constant pressure of mineral oils $(6)$

$$
c_{p}(p, T)=640+4.43 T-\int_{p_{Q}}^{p} T \frac{\partial^{2}}{\partial T^{2}}\left(\frac{1}{p}\right) d p
$$

Specific heat at constant pressure of tap water and HWCF

$$
c_{p}(p, T)=4.18 \times 10^{3}+0.623 \times(T-313)
$$

Thermal conductivity of mineral oils, water and HWCF

$$
\lambda(p, T)=\lambda_{0}\left[1-\alpha\left(T-T_{0}\right)\right]\left[1-\beta\left(p-p_{0}\right)\right]
$$

\begin{tabular}{rrrr} 
Lubricant & $\lambda_{e} w /(m K)$ & $\alpha 1 / K$ & $\beta 1 / r_{\mathrm{a}}$ \\
\hline Mineral oil & $10^{-1}$ & $10^{-3}$ & $10^{-9}$ \\
Water and HWCF & 1.50 & -1.49 & 1.89 \\
& 6.03 & 1.54 & 0.63
\end{tabular}

Thermal conductivity of sea water(12)

$$
\lambda(p, T)=0.55+1.792 \cdot t-0.018 \cdot t^{2}
$$

